\title{
Thyroid function in abnormal uterine bleeding
}

\author{
Ruthvika Kundoor ${ }^{1 *}$, Burri Sandhya Rani²
}

${ }^{1}$ Student, Osmania University, Hyderabad, Telangana, India

${ }^{2}$ Department of Obstetrics and Gynecology, Laxmi Narasimha Hospital, Hanamkonda, Hyderabad, Telangana, India

Received: 05 March 2019

Accepted: 11 April 2019

\section{*Correspondence:}

Dr. Ruthvika Kundoor,

E-mail: ruthvikakundoor@gmail.com

Copyright: () the author(s), publisher and licensee Medip Academy. This is an open-access article distributed under the terms of the Creative Commons Attribution Non-Commercial License, which permits unrestricted non-commercial use, distribution, and reproduction in any medium, provided the original work is properly cited.

\begin{abstract}
Background: AUB is any abnormal uterine bleeding in the absence of any palpable pelvic pathology and demonstrable extra genital causes. AUB is responsible for $10 \%$ of gynaecological complaints. Thyroid hormone is very important to affect the menstrual pattern. The objective of this study was to evaluate thyroid function test in women with AUB and to assess the menstrual pattern in women with thyroid dysfunction.

Methods: The present study was conducted in the Department of Obstetrics and Gynecology, Laxmi Narasimha Hospital, Hanamkonda, Hyderabad, Telangana, India 80 women of reproductive age group between 15-45 years women with menstrual disorders like menorrhagia, oligomenorrhea, hypomenorrhea, polymenorrhea, metrorrhagia, and amenorrhea. Quantitative determination of T3, T4, and TSH by CLIA estimated in autoanlyser.

Results: About 80 women participated in the study in which Most of the subjects belong to 26-30 years of age group. Maximum patients i.e. $41(51.2 \%)$ patients were para one to 2. Commonest cause bleeding pattern was menorrhagia 41.25\%. 15 apparently normal patients with AUB belonged to the category of subclinical hypothyroidism (15\%). Hormonal levels revealing profound hypothyroidism in patients without any symptoms was present in only $10 \%$ of cases. $2.5 \%$ of cases had hyperthyroidism though they were clinically normal. Patients who were sub-clinically hypothyroid were maximally presenting as polymenorrhoea $(50 \%)$ and menorrhagia $(12.1 \%)$ and only $6.27 \%$ of patients had oligomenorrhoea. Patients who were profound hypothyroid were predominantly having polymenorrhagia $(83.3 \%)$ and $(62.5 \%)$ of patients had oligomenorrhoea.

Conclusions: So, biochemical evaluation of thyroid functioning should be made mandatory in all provisionally diagnosed cases of AUB to detect thyroid dysfunction.
\end{abstract}

Keywords: Abnormal uterine bleeding, Thyroid function

\section{INTRODUCTION}

Abnormal uterine bleeding includes both structural and non structural causes. Structural causes are polyp, adenomyosis, fibroids, malignancies and hyperplasia and non-structural causes includes coagulopathy, endometrial causes, iatrogenic and non classified causes. $20 \%$ women in gynaecology present with abnormal uterine bleeding. ${ }^{1}$ Abnormal uterine bleeding is any abnormal uterine bleeding in the absence of any palpable pelvic pathology and demonstrable extra genital causes. It is well recognized that thyroid dysfunction has profound effects on female reproductive system in terms of delayed puberty, AUB, infertility, recurrent pregnancy loss, premature menopause. Thyroid disorders are 10 times more common in females than males. ${ }^{2-4}$ This high prevalence in female is possibly due to autoimmune nature of thyroid disorders. The underlying cause of AUB is uncertain but most common associated basic pathology is ovarian dysfunction and consequent hormonal 
imbalance. Ovarian dysfunction may be primary (pathological lesion of ovary) or secondary to endocrine dysfunction e.g. Hypothalamus, pituitary and thyroid. Various studies have done earlier show that menorrhagia being the chief symptom in hypothyroidism. Majority of cases of subclinical hypothyroidism pass unrecognised because these patients are usually asymptomatic. ${ }^{5,6}$ Prevalence of subclinical hypothyroidism is so high that it should be given enough consideration justifying the screening of women with menstrual irregularities even if they don't have any symptom or sign related to thyroid disorder. ${ }^{7,8}$ Menon has demonstrated the treatment of AUB with thyroxine. ${ }^{9}$ Doifodi and Fernando have also done research to show that unnecessary hormonal treatment and surgeries can be avoided with correction of thyroid disorders. ${ }^{10}$ Serum TSH assay is a sensitive indicator of hypothyroidism because TSH levels elevates before circulating thyroxin level fall below normal range.

Thyroid gland is one of the most vital endocrine organs which plays a major role in growth, development, metabolism and function of every organ in the body. Both Hypo and Hyperthyroidism can result in menstrual irregularities. In women thyroid disorders can cause a broad spectrum of reproductive abnormalities ranging from abnormal sexual development, menstrual irregularities, infertility and premature menopause. Abnormal uterine bleeding is one of the most common, yet complicated clinical presentation. Timely detection of thyroid dysfunction in women presenting with AUB and its proper management can prevent unnecessary surgical interventions and helps to reduce financial burden and improves quality of life. Hence this study is undertaken to evaluate the thyroid dysfunction in women with abnormal uterine bleeding.

The objective of this study was to estimate the prevalence of thyroid dysfunctions in women with AUB from puberty to menopause; and to evaluate thyroid function test in women with AUB; and to assess the menstrual pattern in women with thyroid dysfunction.

\section{METHODS}

The present study was conducted in the Department of Obstetrics and Gynecology, 80 women of reproductive age group 15-45 years were selected.

\section{Inclusion criteria}

Women with menstrual disorders like menorrhagia, oligomenorrhea, hypomenorrhea, polymenorrhea, metrorrhagia, and amenorrhea.

\section{Exclusion criteria}

Patients with menstrual disorder having any known organic pathology like uterine fibroid, adenomyosis, tubercular endometriosis, polyp, uterine malignancy, etc. and patients with IUCD in utero were excluded from study.

After taking detailed history regarding age, parity, age of menarche, menstrual disorders and dysmenorrhea, general physical examination along with pelvic examination was carried out in women with menstrual complaints. Routine basic investigation and thyroid profile that includes $\mathrm{T} 3, \mathrm{~T} 4$ and $\mathrm{TSH}$ was performed in all patients. These tests were done in random blood samples as the variation in TSH secretion due to circadian rhythm is small and does not influence the timing of blood sampling.

Direct quantitative determination of T3, T4, and TSH by CLIA estimated in autoanlyser. In necessary cases special investigations were done as Trans-abdominal scan, endometrial sampling, and hysteroscopy.

\section{Statistical analysis}

Statistical analysis is done by SPSS software and Difference with a $\mathrm{p}$ value of $<0.05$ was considered statistically significant.

\section{RESULTS}

There were 80 women included in the study. The age groups of all the patients are mentioned in Figure 1.

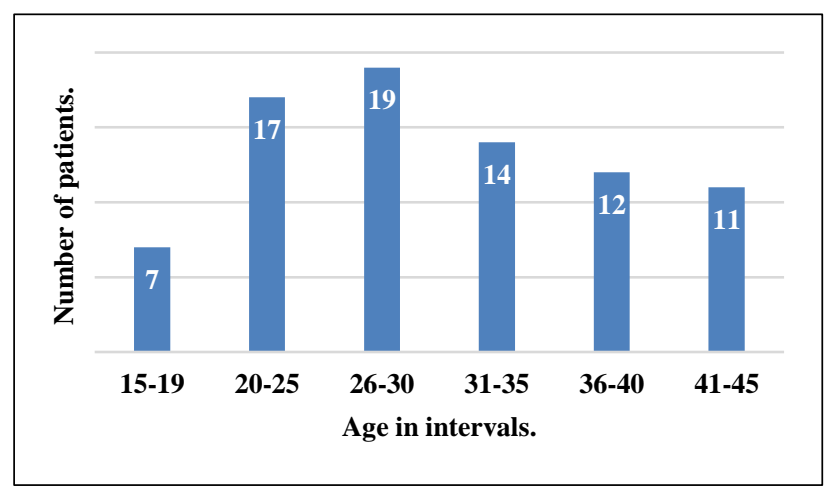

Figure 1: Distribution of patients according to age intervals.

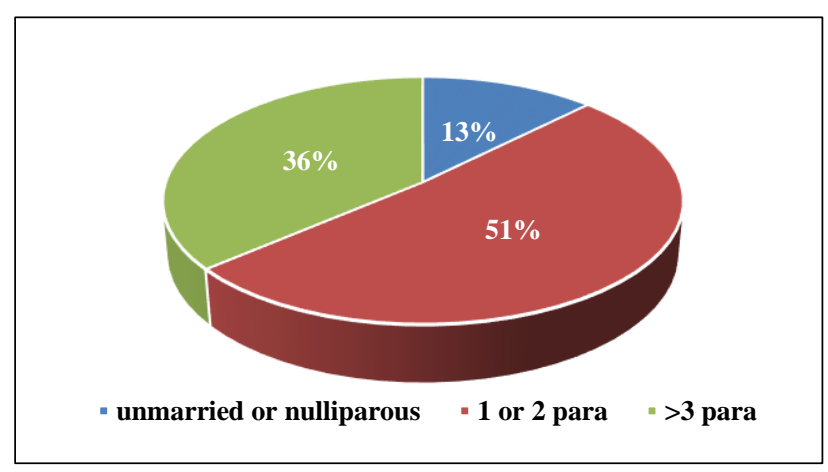

Figure 2: Distribution of subject according to parity. 
Table 1: Distribution of subjects according to bleeding pattern.

\begin{tabular}{|lll|}
\hline Type of bleeding & No. of patients & $\%$ \\
\hline Acyclical & 15 & 18.75 \\
\hline Hypomenorrhoea & 2 & 2.5 \\
\hline Menorrhagia & 33 & 41.25 \\
\hline Oligomenorrhoea & 16 & 20 \\
\hline Polymenorrhagia & 12 & 15 \\
\hline Polymenorrhoea & 2 & 2.5 \\
\hline Total & 80 & 100 \\
\hline
\end{tabular}

Most of the subjects belong to 26-30 years of age group. Next most common group in study is 20-25 years showing 20-35 years age group are most effected group in study. Among 80 cases of AUB, 10 (12.5\%) patients were unmarried or nulliparas. $41(51.2 \%)$ patients were para one to $2.29(36.2 \%)$ patients were greater para 3 . In this study maximum numbers of patients were para one to 2.

Table 2: Distribution of subjects according to thyroid function.

\begin{tabular}{|lll|}
\hline Thyroid function & No. of cases & $\%$ \\
\hline Euthyroid & 58 & 72.5 \\
\hline Hypothyroid & 8 & 10 \\
\hline subclinical hypothyroid & 12 & 15 \\
\hline Hyperthyroid & 2 & 2.5 \\
\hline Total & 80 & 100 \\
\hline
\end{tabular}

Commonest was menorrhagia $41.25 \%$. Others $18.7 \%$ presented with acyclical, $20 \%$ with oligomenorrhoea.

Table 3: Bleeding pattern in accordance with thyroid function.

\begin{tabular}{|lllllllllll|}
\hline Type of bleeding & $\begin{array}{l}\text { No. of } \\
\text { cases }\end{array}$ & Euthyroid & $\%$ & Hypothyroid & $\%$ & $\begin{array}{l}\text { Subclinical } \\
\text { hypothyroid }\end{array}$ & Hyperthyroid & \% \\
\hline Acyclical & 15 & 12 & 80 & 2 & 13.3 & 1 & - & 6.7 & - & - \\
\hline Hypomenorrhoea & 2 & 2 & 100 & - & - & - & - & - & - \\
\hline Menorrhagia & 33 & 21 & 63.6 & 7 & 21.2 & 4 & 12.1 & 1 & 3 \\
\hline Ologomenorrhoea & 16 & 3 & 18.7 & 10 & 62.5 & 1 & 6.27 & 2 & 12.5 \\
\hline Polymenorrhagia & 12 & - & - & 10 & 83.3 & 1 & 7.6 & 1 & - \\
\hline Polymenorrhoea & 2 & - & - & 1 & 50 & 1 & 50 & - & - \\
\hline
\end{tabular}

About 15 apparently normal patients with AUB belonged to the category of subclinical hypothyroidism (15\%). Hormonal levels revealing profound hypothyroidism in patients without any symptoms was present in only $10 \%$ of cases. $2.5 \%$ of cases had hyperthyroidism though they were clinically normal.

Patients who were sub-clinically hypothyroid were maximally presenting as polymenorrhoea (50\%) and menorrhagia $(12.1 \%$ ) and only $6.27 \%$ of patients had oligomenorrhoea. Patients who were profound hypothyroid were predominantly having polymenorrhagia $(83.3 \%)$ and $(62.5 \%)$ of patients had oligomenorrhoea.

\section{DISCUSSION}

Menorrhagia is a frequent symptom in gynaecological practice resulting in need for repeated curettage and hysterectomy with its relative morbidity and mortality. Menstrual blood loss is considered to be excessive when it is greater than $80 \mathrm{ml}$ per cycle.

The aetiology of menorrhagia is much differential diagnosis. It may be due to systemic conditions like hormonal imbalance like hypothyroidism and hyperthyroidism, or lesions of genital tract like endometrial hyperplasia, pelvic inflammatory disease, endometriosis, benign tumours (leiomyoma, polyps) and malignant tumours (endometrial carcinoma). In more than half of the subjects the cause is usually not apparent.

Thyroid dysfunction is one of the common causes of excessive menstrual blood loss and menstrual irregularities (Table 2). It may also lead to anovulation, infertility and recurrent abortion. The onset of hypothyroidism is so insidious that classic clinical manifestation may take months and years to appear. ${ }^{8}$ Furthermore menorrhagia may be the only presenting complain in hypothyroid women. ${ }^{9}$

With the advent of modern hormonal assay techniques precise estimation of thyroid hormones in serum is possible in a rapid and reliable manner. Treatment of hypothyroidism is very satisfying as it usually relieves patient of all the symptoms.

Hence, in investigating a patient with menorrhagia and/or menstrual irregularities, evaluation of thyroid functional status forms an essential component. Early detection of hypothyroidism in such subjects saves the patient from recurrent curettage and at times hysterectomy. 
Table 4: Bleeding pattern in comparison with other studies.

\begin{tabular}{|c|c|}
\hline Menorrhagia in hypothyroidism & Percentage \\
\hline Doifode et al ${ }^{10}$ & 63.30 \\
\hline Singh et $\mathrm{al}^{11}$ & 44.40 \\
\hline Wilansky and Bernard ${ }^{12}$ & 100 \\
\hline Deshmukh PY et al ${ }^{13}$ & 32.40 \\
\hline Present study & 21.30 \\
\hline \multicolumn{2}{|l|}{ Oligomenorrhoea } \\
\hline Singh et al $^{11}$ & 64 \\
\hline Deshmukh PY et al ${ }^{13}$ & 66.60 \\
\hline Present study & 62.50 \\
\hline
\end{tabular}

Thyroid disorders are more common in women with menstrual irregularities as compared to general population. 80 women participated in the study in which Most of the subjects belong to 26-30 years of age group (Figure 1). Maximum patients i.e 41 (51.2\%) patients were para one to 2 . Commonest cause bleeding pattern was menorrhagia $41.25 \%$. 15 apparently normal patients with AUB belonged to the category of subclinical hypothyroidism (15\%) (Table 1). Hormonal levels revealing profound hypothyroidism in patients without any symptoms was present in only $10 \%$ of cases. $2.5 \%$ of cases had hyperthyroidism though they were clinically normal. Patients who were sub-clinically hypothyroid were maximally presenting as polymenorrhoea (50\%) and menorrhagia $(12.1 \%)$ and only $6.27 \%$ of patients had oligomenorrhoea (Table 2). Patients who were profound hypothyroid were predominantly having polymenorrhagia $(83.3 \%)$ and $(62.5 \%)$ of patients had oligomenorrhoea (Table 3).

Gowri $\mathrm{M}$ et al, showed prevalence of hypothyroidism in women in the reproductive age (20-40years) varies between $2 \%$ and $4 \% .{ }^{14}$ In the general population, the prevalence of subclinical hyperthyroidism is approximately $1.5 \% .^{17}$ In the present study, $17.6 \%$ of women were hypothyroid, $2.7 \%$ had sub clinical hypothyroidism and $4.7 \%$ had hyperthyroidism.

Joshi et al, found $68 \%$ of menstrual abnormalities in 22 women with hypothyroidism compared to only $12 \%$ in 49 controls. ${ }^{15,18}$ In the study by Krassas et al, the prevalence of menstrual irregularities (mainly oligomenorrhoea) reached $23 \%$ among 171 hypothyroid patients, while being only $8 \%$ in 214 controls $(\mathrm{P}<0.05) .{ }^{16}$ There were also $12 \%$ of women presenting with amenorrhoea in the hypothyroid group, and none among the control subjects. The most common menstrual irregularity in our study was oligomenorrhoea followed by menorrhagia.

Table 5: Type bleeding in comparison with Deshmukh PY et al.

\begin{tabular}{|lllll|}
\hline Type of bleeding & Number of patients & Percentage & Deshmukh PY et al ${ }^{13}$ & Percentage $^{18}$ \\
\hline Acyclical & 15 & 18.75 & 18 & 2 \\
\hline Hypomenorrhoea & 2 & 2.5 & 2 & 40 \\
\hline Menorrhagia & 33 & 41.25 & 15 & 15 \\
\hline Ologomenorrhoea & 16 & 20 & 18 & 18 \\
\hline Polymenorrhagia & 12 & 15 & 4 & 4 \\
\hline Polymenorrhoea & 2 & 2.5 & 100 & 100 \\
\hline Total & 80 & 100 & & 40 \\
\hline
\end{tabular}

Women with history of recurrent abortions, postpartum psycosis women with sub clinical hypothyroidism, infertility, associated with menstrual irregularities are all to be screened for thyroid dysfunction. Targeted screening at regular intervals should be recommended. This should also be considered in women who have had gynaecological and/or obstetric complications associated with hypothyroidism and in whom treatment is shown to be beneficial.

So, screening selected subject groups is could be justified, based on the significant risks to offspring, the probable benefit of treatment, and the probable low incidence of adverse outcomes from intervention.

\section{CONCLUSION}

As there is high incidence of thyroid diseases in women with abnormal uterine bleeding are to be screened. This would also avoid unnecessary hormonal treatment and surgery in these patients. It concludes that thyroid disorder should be considered as an important aetiological factor for menstrual abnormality.

Thus, biochemical evaluation T3, T4 and TSH estimations should be made mandatory in AUB cases to detect profound and subclinical thyroid dysfunction.

Funding: No funding sources

Conflict of interest: None declared

Ethical approval: The study was approved by the Institutional Ethics Committee

\section{REFERENCES}

1. Nesse $\mathrm{R}$, Abnormal vaginal bleeding in premenopausal women. Am Family Physian. $1984 ; 40 ; 185$. 
2. Davey DA, Dewhurst. Text book of obstetrics and gynaecology for post graduates. $5^{\text {th }}$ edn; 1990:590600.

3. Thomas R, Reid RL. Thyroid disease and reproductive dysfunctions. Obstet Gynaecol. 1987;70:789-98.

4. Berek JS, Adarshi EY, Hillard PA. In endocrine disorders. Novaks Gynaecology $12^{\text {th }}$ edn. Williums and Wilkins, Gopson paper ltd Noida; 2001: 864.

5. Olive D, Palter S. Reproductive Physiology. In: Berek JS, eds. Berek and Novak's Gynaecology. 14 $4^{\text {th }}$ ed Philadelphia: Lippincott Williams and Wilkins Company; 2002: 161-86.

6. Thomas R. Reid RL. Thyroid diseases and reproductive dysfunction. Obstet Gynaecol. 1987;70:789-98.

7. ACOG Practice bulletin: Management of anovulatory bleeding. Int $\mathbf{J}$ Gynaecol Obstet. 2001;72:263-71.

8. Fraser IS, Langham S, Hoschgraebes K. Health related quality of life and economic burden of abnormal uterine bleeding. Expert Review Obstet Gynaecol. 2009;4(2):179-89.

9. Menon VK, Baruch KE. Menstrual dysfunction and thyroid disease. J Obstet Gynae India. 1995;45(4);521-6.

10. Doifode CD, Fernandes K. Study of thyroid dysfunction in patients with Abnormal uterine bleeding. J Obstet Gynecol India. 2001;51:93-5.
11. Singh L, Agarwal CG, Choudhary SR, Mehra P, Khare R. Thyroid profile in infertile woman. J Obstet Gynecol India. 1990;40:248.

12. Wilansky DL, Greisman B. Early hypothyroidism in patients of menorrhagia. Am J Obstet Gynaecol. 1989;3:673-7.

13. Deshmukh PY. The association of thyroid disorders with abnormal uterine bleeding. Int $\mathbf{J}$ Reprod Contracept Obstet Gynecol. 2015;4(3):701-8.

14. Gowri M, Radhika BH, Harshini V, Ramaiaha R. Role of thyroid function tests in women with abnormal uterine bleeding. Int J Reprod Contracept Obstet Gynecol. 2014;3:54-7.

15. Joshi JV, Bhandarkar SD, Chadha M, Balaiah D, Shah R. Menstrual irregularities and lactation failure may precede thyroid dysfuction or goitre. J Postgraduate Med. 1993;39:137-41.

16. Kaltsas J, Paunkovic N, Kaltsas T, Papadopoulou P, Paunkovic J. Disturbances of menstruation in hypothyroidism. Clin Endocrinol. 1999;50:655-9.

Cite this article as: Kundoor R, Rani BS. Thyroid function in abnormal uterine bleeding. Int J Reprod Contracept Obstet Gynecol 2019;8:2270-4. 